\title{
El sentido de la vida en los relatos de discontinuidad de la carrera delictiva: análisis cualitativo de dos casos
}

\section{The meaning of life in the stories of discontinuity \\ of the criminal career: qualitative analysis of two cases \\ O sentido da vida nas histórias de descontinuidade \\ da carreira criminosa: análise qualitativa de dois casos}

Fecha de recepción: 2020/05/25 | Fecha de evaluación: 2020/I I/05 | Fecha de aprobación: 202 I/01/04

Adrián Jiménez-Ribera

Escuela de Doctorado. Universidad Católica de Valencia San Vicente Mártir Beneficiario de la Beca para la Formación de Profesorado Universitario del Ministerio de Ciencia, Innovación y Universidades de España
Joaquín García-Alandete

Facultad de Psicología Universidad Católica de Valencia San Vicente Mártir Beneficiario de la Beca para la Formación de Profesorado Universitario del Ministerio de Ciencia, Innovación y Universidades de España joaquin.garcía-alandete@uv.es

Para citar este artículo / To reference this article / Para citar este artigo: Jiménez-Ribera, A. \& García-Alandete, J. (202I). El sentido de la vida en los relatos de discontinuidad de la carrera delictiva: análisis cualitativo de dos casos. Revista Criminalidad, 63(2), 33-5I. https://doi.org//0.4774I//7943108.315

\section{Resumen}

El estudio de la relación entre el sentido de la vida y la persistencia o desistimiento de la carrera delictiva, así como su aplicabilidad en el tratamiento de delincuentes, han recibido escasa atención en el ámbito de la criminología. El objetivo del presente trabajo consistió en explorar la presencia o ausencia del sentido de vida desde el paradigma de la criminología narrativa. Para ello, estudiamos los relatos de dos varones españoles con extensa carrera delictiva: uno que dejó de delinquir hace $2 \mathrm{l}$ años y otro que persiste en la actualidad. Se llevó a cabo un análisis cualitativo sobre tres categorías indicadoras del sentido de vida: comprensión de la propia vida, propósito de vida y sentimiento de importancia. Los resultados indicaron que el relato de desistimiento contenía múltiples referencias al hallazgo de un sentido de vida, en tanto que el entrevistado observó que su hallazgo contribuyó a la finalización del comportamiento ilícito. Por el contrario, el relato de persistencia destacó una experiencia de vacío existencial, la cual condicionaba la continuidad delictiva. Los programas de intervención, cuyo propósito es la prevención de la delincuencia o de la reincidencia, podrían beneficiarse de las aportaciones de un modelo centrado en el sentido de la vida que favorezca el desarrollo de nuevas narrativas resilientes.

\section{Palabras clave}

Carrera delictiva, desistimiento, persistencia, sentido de la vida, criminología narrativa (fuente: Tesauro Criminológico - Instituto Interregional de las Naciones Unidas para Investigaciones sobre la Delincuencia y la Justicia - UNICRI). 


\section{Abstract}

The study of the relationship between the meaning of life and the persistence or withdrawal of the criminal career, as well as its applicability in the treatment of offenders, has received little attention in the field of Criminology. The aim of this work was to explore the presence or absence of the meaning of life from the paradigm of narrative criminology. To do this, we studied the stories of two Spanish men with extensive criminal careers: one who stopped committing crimes 21 years ago and another who persists today. A qualitative analysis was carried out on three categories indicating the meaning of life: understanding of one's own life, life purpose and feeling of importance. The results indicated that the withdrawal report contained multiple references to the finding of a sense of life, while the interviewee observed that its finding contributed to the end of the illicit behavior. On the contrary, the story of persistence highlighted an experience of existential emptiness, which conditioned the criminal continuity. Intervention programmes, whose purpose is the prevention of crime or recidivism, could benefit from the contributions of a model focused on the meaning of life that favours the development of new resilient narratives.

\section{Keywords}

Criminal career, desisting, persistence, meaning of life; narrative criminology (source: Criminological Thesaurus - United Nations Interregional Crime and Justice Research Institute - UNICRI).

\section{Resumo}

O estudo da relação entre o sentido da vida e a persistência ou retirada da carreira criminosa, bem como sua aplicabilidade no tratamento dos infratores, tem recebido pouca atenção no campo da Criminologia. O objetivo deste trabalho foi explorar a presença ou ausência do sentido da vida a partir do paradigma da criminologia narrativa. Para isso, estudamos as histórias de dois espanhóis com extensas carreiras criminosas: um que parou de cometer crimes há $2 \mathrm{I}$ anos e outro que persiste até hoje. Uma análise qualitativa foi realizada em três categorias indicando o sentido da vida: compreensão da própria vida, propósito de vida e sentimento de importância. Os resultados indicaram que $\circ$ relatório de retirada continha múltiplas referências à constatação de um sentido de vida, enquanto o entrevistado observou que seu achado contribuiu para o fim do comportamento ilícito. Pelo contrário, a história da persistência destacou uma experiência de vazio existencial, que condiz com a continuidade criminal. Os programas de intervenção, cujo objetivo é a prevenção do crime ou da reincidência, poderiam beneficiar-se das contribuições de um modelo focado no sentido da vida que favoreça o desenvolvimento de novas narrativas resilientes.

\section{Palavras-chave}

Carreira criminosa, abstinência, persistência, sentido da vida, criminologia narrativa. (fonte: Thesaurus Criminológico Instituto Inter-regional de Pesquisa em Crime e Justiça das Nações Unidas - UNICRI).

\section{Introducción}

\section{La carrera delictiva: persistencia y desistimiento}

El concepto de 'carrera delictiva' comprende toda aquella secuencia de comportamientos antisociales $\mathrm{e}$ infractores cometidos por un individuo a lo largo del tiempo, así como los factores asociados a tales conductas (Redondo, 2017). Toda carrera delictiva se compone de tres etapas: (I) inicio de la actividad delictiva, (2) persistencia e incremento del comportamiento criminal (esto es, continuidad y reincidencia de las acciones antisociales, cuya duración es variable) y (3) desistimiento, entendido como el cese de la delincuencia (Piquero et al., 2013; Redondo, 2017; Redondo \& Garrido, 2013; Thornberry et al., 2013).

En la actualidad existe un elevado interés en el estudio de los procesos y factores subyacentes tras 
el mantenimiento o abandono de la carrera delictiva, ya que su conocimiento puede contribuir al desarrollo de programas para la prevención de la reincidencia. Sin embargo, no existe una teoría capaz de explicar, de manera unánime, todos los aspectos implicados en el desarrollo de tales etapas (Cid \& Martí, 20I I; Kazemian \& Maruna, 2009; LeBel et al., 2008; Redondo, 2017; Redondo \& Garrido, 2013; Rocque, 2017; Sweeten \& Khade, 2018; Thornberry et al., 2013; Weaver, 2019).

Numerosos estudios han observado que la continuidad o finalización de la conducta delictiva se encuentra condicionada por diversos factores sociales o estructurales, de manera que mientras un individuo se encuentre bajo la influencia de un entorno que promueva el comportamiento ilícito (p. ej., en compañía de amistades delictivas o en un contexto de precariedad económica y abuso de sustancias), es probable que tal conducta se mantenga (p. ej., Agnew, 1992, 2009; Akers, 20II; Thornberry et al., 20I3). Por el contrario, el distanciamiento de estos factores de riesgo y la consolidación de nuevos vínculos con la sociedad convencional, a través de 'puntos de inflexión' en la vida del sujeto (p. ej., consecución de un empleo, matrimonio o paternidad) pueden estimular la finalización de la trayectoria delictiva ( $p$. ej., Cid \& Martí, 20II, 2012; Laub \& Sampson, 2003; Martens, 2017; Sampson \& Laub, 1993).

Sin embargo, la mera exposición a tales circunstancias sociales favorables, por sí sola, podría no ser suficiente para propiciar el desistimiento (p. ej., Gadd \& Farrall, 2004; Maruna, 200I, 2004; Kazemian \& Maruna, 2009; LeBel et al., 2008; Redondo, 2017; Weaver, 2019), además de que su impacto podría variar según el grado de motivación personal, la apertura al cambio o la interpretación sobre el propio estilo de vida (Gadd \& Farrall, 2004; Giordano et al., 2002; Giordano et al., 2007; Paternoster et al. 2015; Paternoster \& Bushway, 2009; Rocque, 2017; Sampson \& Laub, 2005; Weaver, 2019). En consecuencia, el desistimiento suele verse precedido por cambios en la identidad $y$ en el concepto que se tiene sobre el comportamiento ilícito (p. ej., Doekhie et al., 2017; Giordano et al., 2002, 2007; King, 2013; Paternoster et al., 2015; Paternoster \& Bushway, 2009; Liem \& Richardson, 2014). Tal proceso queda reflejado en la construcción de una nueva narrativa de vida en la que el sujeto reinterpreta su pasado delictivo y la persona que es en la actualidad, y formula expectativas de futuro al margen de la conducta delictiva (Bove \& Tryon, 2018; Cid \& Martí, 20I I, 2012; Doekhie et al., 2017; King, 2013; Martín et al., 2019; Maruna, 200I; Presser \& Sandberg, 2015).
Criminología narrativa: efectos de los relatos autobiográficos sobre la carrera delictiva

La criminología narrativa ha emergido durante la última década como una disciplina dedicada al estudio del impacto que tienen las narraciones que los delincuentes construyen sobre ellos mismos en su conducta (Presser, 2016; Presser \& Sandberg, 2015, 2019; Sandberg \& Ugelvik, 2016). Sus fundamentos se hayan en la psicología narrativa, la cual entiende que, al reconstruir sus vidas de manera narrativa, las personas establecen conexiones entre sus experiencias, sus relaciones con otros individuos, sus acciones y aspiraciones, esto les hace consolidar su autoconcepto o 'identidad' como un único individuo moral consistente a lo largo del relato o un conjunto de identidades distintas que se unifican en una sola entidad (McAdams, 2018; McAdams \& McLean, 20I3; Popp-Baier, 20I3; Presser \& Sandberg, 2015; Sandberg \& Ugelvik, 2016). Este autoconcepto construido a través de las narraciones condicionaría el comportamiento futuro, puesto que las respuestas que ofrece a los estímulos y experiencias del entorno deben ser coherentes, consistentes y congruentes con la identidad desarrollada a través del relato (Bove \& Tryon, 2018; Doekhie et al., 2017; King, 2013; Maruna, 200I; Presser, 2016; Presser \& Sandberg, 2015).

La influencia de los relatos de vida sobre la continuidad o finalización de la carrera delictiva ha sido ampliamente documentada en la literatura criminológica (p. ej., Bove \& Tryon, 2018; Cid \& Martí, 20II; Doekhie et al., 2017; King, 20I3; Liem \& Richardson, 2014; Maruna, 200I; Martens, 2017; Presser \& Sandberg, 2015; Presser, 2016), de manera que numerosos estudios señalan que la formulación de una nueva identidad narrativa prosocial constituye un elemento indispensable para el abandono de la persistencia ilícita (p. ej., Giordano et al., 2002, 2007; LeBel et al., 2008; Maruna, 200 I, 2004; Paternoster \& Bushway, 2009; Paternoster et al., 2015).

Aquellos que desisten suelen construir narrativas en las que expresan una visión optimista de futuro, sentimiento de autorrealización, percepción de control sobre su propia vida y confianza en sí mismos para evitar la recaída en la delincuencia (p. ej., Cid \& Martí, 20II; LeBel et al., 2008; Maruna, 200I, 2004; Sweeten \& Khade, 2018). Por el contrario, quienes persisten tienden a mostrar una perspectiva vital pesimista (o falta de visión de futuro), así como una actitud pasiva, marcada por una convicción de ser 
incapaces de dejar de delinquir debido a su entorno o a sus circunstancias personales (p. ej., Doekhie et al., 2017; Martens, 2017; Maruna, 200I; Sweeten \& Khade, 2018). Además, recientes estudios advierten que el desarrollo de estos tipos de relatos en los primeros meses de cumplimiento de condena se correlaciona con la futura continuidad o finalización de la trayectoria criminal (p. ej., Doekhie et al., 2017; Howerton et al., 2009; King, 2013; Martín et al., 2019; Souza et al., 2013).

A pesar de estos resultados, en la actualidad son pocos los programas de tratamiento y medidas de intervención dirigidos a estudiar y estimular el desarrollo de tales narrativas y los factores específicos de protección reflejados en las mismas que favorecen y predicen la reinserción social (Bove \& Tryon, 2018; Doekhie et al., 20 17; McNeill et al., 2012; Ward, 20I7).

\section{Intervención para el desistimiento: una perspectiva focalizada en los factores de protección}

Muchos programas actuales de tratamiento sobre delincuentes se sustentan sobre los planteamientos del modelo de Riesgos-Necesidades-Responsividad (Andrews \& Bonta, 2016), el cual se fundamenta en la intervención sobre las necesidades criminógenas - factores de riesgo susceptibles de cambio directamente correlacionados con el comportamiento antisocial (hábitos, cogniciones, actitudes delictivas, etc.) (Redondo, 2017; Redondo et al., 2012). Si bien este modelo ha sido empíricamente respaldado por múltiples estudios, también ha sido objeto de críticas, ya que concibe al delincuente como un sujeto pasivo cuya conducta y potencial de cambio están determinados por la influencia de factores ajenos a su voluntad (McNeill et al., 2012; Rocque, 2017; Ward \& Maruna, 2007; Ward et al., 2012).

Estas críticas han llevado en los últimos años a un interés creciente sobre el estudio y aplicabilidad de los factores de protección en el tratamiento de delincuentes, tales como la autonomía, la resiliencia, los propósitos vitales o el apoyo social (p. ej., De Vries et al., 2015; Ward, 2017). Tal interés deriva de la teoría de la rehabilitación Good Lives, que formularon Ward (2002) y Ward y Maruna (2007). Los autores proponen un tratamiento focalizado en el desarrollo, la motivación personal y el capital humano como elementos preventivos de la delincuencia: plantean que el estímulo y potenciación de tales elementos y otros factores de protección pueden favorecer la prevención terciaria, ya que ayudan a mitigar la influencia de los factores de riesgo que promueven la actividad ilícita (Ward, 2017; Ward et al., 20I2).

Ward (2002), Ward et al. (20I2) y Ward y Maruna (2007) argumentan que, a través de sus conductas, las personas se orientan a alcanzar determinados objetivos o bienes primarios (bienestar, felicidad, estabilidad económica, etc.), resultando la conducta antisocial de la incapacidad para alcanzarlos o del empleo de estrategias erróneas (Ward et al., 2012; Ward \& Gannon, 2006). En consecuencia, las intervenciones fundamentadas en el modelo Good Lives se dirigen a auxiliar a los delincuentes a satisfacer tales bienes y potenciar sus virtudes y fortalezas para alcanzarlas de manera cívica, lo cual prevendría el comportamiento delictivo. Por ende, se concibe al delincuente como agente protagonista en su cambio.

Entre su clasificación de bienes humanos primarios, los autores destacan la necesidad de las personas de encontrar un significado y un propósito de vida (Ward et al., 2012; Ward \& Gannon, 2006; Ward \& Maruna, 2007). No obstante, a día de hoy, la literatura acerca de la relación entre sentido de la vida con la conducta delictiva es prácticamente inexistente. Más todavía, no existe ningún programa de intervención específico para delincuentes dirigido a su estímulo, en aras de la reinserción.

\section{Sentido de la vida y conducta delictiva}

Según Viktor Emil Frankl, fundador de la logoterapia, la principal motivación humana es encontrar un sentido a la propia vida (voluntad de sentido) y, cuando no se logra, se puede experimentar el vacío existencial (Frankl, 2003, 2004). Mientras que una vida plena de sentido implica la autodeterminación, está basada en la autotrascendencia y orientada a la realización de valores positivos y autorrealizativos, una vida sin sentido está encaminada a valores disfuncionales, que satisfacen la voluntad de éxito, poder y placer, dando lugar a una vida solo aparentemente realizada. Asimismo, mientras que la presencia de sentido se caracteriza por el optimismo, la esperanza, la responsabilidad sobre la propia vida y la proactividad, el vacío existencial se caracteriza por el pesimismo, la desesperanza, el conformismo, el fatalismo y la atribución de responsabilidad a factores ambientales, dificultando que la persona pueda efectuar cambios positivos en su vida.

Para Frankl (2004) la persona no está nunca totalmente determinada en su conducta por la herencia genética $o$ sus circunstancias sociales (culturales, económicas, educativas, etc.), sino 
que siempre, como ser libre que es (libertad de la voluntad), tiene un margen de autodeterminación (Frankl considera a la persona, por ello, un ser condicionadamente condicionado: las circunstancias condicionan, pero no determinan). Más todavía, las circunstancias adversas pueden servir de ocasión para activar recursos (personales y sociales) para un afrontamiento positivo. Es lo que Frankl (2000) denominó 'optimismo trágico'. Frankl (2004) planteó que determinadas conductas antisociales podían estar vinculadas con el vacío existencial (p. ej., la adicción a sustancias y la criminalidad juvenil) (cfr. Addad \& Himi, 2013; Csabonyi \& Phillips, 2020), y que podían beneficiarse de una intervención basada en el sentido. La persistencia y el desistimiento de la conducta delictiva podrían asociarse significativamente al vacío existencial y la presencia de sentido, respectivamente, según sugieren distintos estudios.

Black y Gregson (1973), en un estudio en el que comparaban 30 convictos reincidentes, 30 convictos de primer ingreso en prisión y 30 sujetos sin historial de ingreso en prisión, encontraron (I) que los primeros mostraban un sentido de la vida más bajo que los segundos, y estos que los terceros; (2) que su orientación existencial en clave temporal era diferente: los dos primeros grupos estaban centrados en el presente, y el tercero en el futuro; y (3) que el historial de encarcelamiento previo no había disuadido a los reincidentes de seguir delinquiendo ni había incrementado su sentido de la vida. La presencia de sentido, concluyeron, está inversamente relacionada con la criminalidad, en la línea de lo que estableció Frankl (2004).

Maruna (200I) halló que un grupo de desistentes mostraban un relato de redención caracterizado por el optimismo trágico, manifestando su creencia de que el sufrimiento les había fortalecido de alguna manera y ayudado a descubrir un nuevo rol o propósito personal, de manera que podían integrar sus errores pasados de una forma coherente con una nueva identidad prosocial que habían consolidado. Según Maruna (200I) esta capacidad de construir una narrativa resiliente y de sentimiento de valía de la vida propia era un elemento clave en los relatos de redención para el abandono de la persistencia delictiva. Asimismo, este autor destacó, como uno de los factores más influyentes para promover el desistimiento, la percepción de que con los actos personales se estaban realizando aportaciones a la comunidad y cambios significativos en la vida de otros, esto es, la creación de objetivos y propósitos centrados en otros. Esto sería expresión de la autotrascendencia que, para Frankl (2004), va ligada a la presencia de sentido $y$, por ello mismo, a la satisfacción con la propia vida y la experiencia de autovalía y autorrealización. La identidad criminal se veía sustituida por una identidad y conducta prosociales, las cuales les permitían redimir la culpabilidad y la vergüenza sentidas por sus acciones pasadas. Por otra parte, este cambio se vinculaba a un sentimiento de libertad y control sobre sus propias vidas (autodeterminación, entendida como la capacidad personal de decidir cómo comportarse, sin someterse a la influencia de los factores condicionantes de su entorno), estando ello relacionado con el papel que a la libertad (libertad de la voluntad) le asignara Frankl (2004) respecto al sentido de la vida. En contraste, Maruna (200I) encontró que algunos de los participantes en su estudio iniciaron la actividad delictiva como una forma de lidiar con un sentimiento de vacío existencial. En definitiva, quienes cesaron su carrera delictiva construyeron un relato de redención en el que exhibían un sentimiento de control sobre su vida y una visión optimista (sin delincuencia) de su futuro, adquirieron una visión resiliente sobre sus experiencias traumáticas y errores pasados, considerándolos precursores necesarios de su bienestar actual. Por el contrario, quienes mantenían un relato de continuidad delictiva manifestaban una actitud pesimista y pasiva de cara a la vida, autopercibiéndose incapaces de cambiar su comportamiento delictivo debido a la influencia de su entorno.

En un estudio posterior, Maruna (2004) señaló que para que se produzca un cese exitoso de la actividad delictiva resulta imprescindible que el individuo construya un relato en el que exprese su capacidad, responsabilidad y confianza para realizar los cambios necesarios en su identidad y conducta.

Eryilmaz (20I8), en un estudio con 50 delincuentes y 50 no delincuentes varones entre 19 y 26 años, encontró que los primeros tenían más dificultades para establecer metas vitales, un componente del sentido de la vida (Reker, 2000), y que la presencia de sentido en los delincuentes podía entenderse en clave de "selección natural" (en términos de poder y supervivencia), toda vez que relacionaba la carrera delictiva con el hecho de haber tenido una familia desorganizada, condiciones ambientales desfavorables, contar con pares no ejemplares y tener patrones de personalidad antisocial (variables todas ellas que contribuían a su "alienación social"). No obstante, algunos delincuentes mostraban también un cierto sentido de control personal sobre esos factores negativos, lo cual podría ser un factor positivo para el proceso de desistimiento $y$ a tener en cuenta en los programas de intervención. 
El objetivo del presente trabajo consistió en el análisis comparativo de los relatos de vida de dos varones españoles en diferentes momentos de la carrera delictiva: persistencia y desistimiento. Se hipotetizó que el caso de desistimiento el sujeto incluiría en el relato elementos indicativos de presencia de sentido, mientras que, el caso de persistencia estaría caracterizado por contenidos indicativos de vacío existencial.

\section{Método}

\section{Diseño}

Se llevó a cabo una investigación cualitativa basada en entrevistas (Benítez et al., 2019) realizadas a dos participantes con un perfil sociodemográfico y carrera delictiva relativamente similares, actualmente en una situación diferente en relación con la misma: desistimiento y persistencia de la actividad ilícita.

\section{Participantes}

Participaron dos varones españoles con carrera delictiva prolongada: (I) Manuel (64 años), que dejó de delinquir hace 21 años tras cumplir condena por una tentativa de homicidio (es decir, a los 43 años de edad), y (2) Luis (54 años), que cumplió su última condena en junio de 2019 por múltiples robos y agresiones a su pareja, si bien a día de hoy persiste en la delincuencia (los nombres usados en este trabajo no son reales). La elección de estos dos participantes respondió a las similitudes en su perfil delictivo, ya que su trayectoria criminal podía ser categorizada como 'persistente desde la juventud a la edad adulta' (Moffitt, 1993; Redondo, 2017): ambos crecieron en un barrio marginal (donde aún mantenían su convivencia) y una situación familiar de precariedad económica. Manuel y Luis iniciaron su actividad ilícita en la preadolescencia (a los 13 y 14 años, respectivamente) y la tipología de sus conductas obedecía a lo que Maruna (200l, p. 62) acuñó como "oportunistas de la delincuencia callejera" o "generalistas" (principalmente delitos cometidos contra la salud pública y el patrimonio para subsistir y costear su consumo de drogas).

Ambos participantes refirieron, en el momento de realizar el presente trabajo, que disponían de un núcleo familiar consolidado, de manera que convivían en su hogar con su pareja (la cual también tuvo una actividad ilícita y drogodependiente en el pasado), con la que mantenían una relación de al menos cinco años. Más aún, Manuel refirió la tenencia de una hija (si bien no convivía con ella). En el momento de la entrevista, tanto Manuel como Luis se encontraban desempleados, si bien percibían un ingreso económico por su minusvalía y por el paro, respectivamente (menos de 500 mensuales). Su nivel de estudios era primario.

Los entrevistados informaron de un inicio temprano en el consumo de drogas (Manuel a los 12 años y Luis a los 15 años). Señalaron que su actividad delictiva estaba estrechamente vinculada con el abuso de las sustancias, ya que gran parte de actos cometidos se vieron propiciados por el síndrome de abstinencia o por su necesidad de obtener dinero para pagarse el consumo. Refieren haber abusado de toda clase de sustancias, destacando la dependencia a la heroína. En el momento de realizar el presente estudio, Manuel afirmó un abandono íntegro de cualquier sustancia, si bien Luis informó de abuso de alcohol (entre uno y dos paquetes de cerveza diario) y consumo esporádico (al menos una vez por semana) de cocaína esnifada.

Ambos presentaban prolongada actividad delictiva (Manuel, 32 años y Luis, 39 años) y refirieron que sus primeros delitos fueron robos de vehículos, o en domicilios y tiendas, por la influencia de amistades y el barrio marginal en el que vivían. Posteriormente, su carrera criminal se vio principalmente marcada por el tráfico de estupefacientes y la comisión de robos con fuerza o violencia, los cuales llegaron a cometer a diario en determinados momentos de su vida. Manuel cumplió condena en prisión en cuatro ocasiones, mientras que Luis lo hizo siete veces. En el momento de realizar este estudio, Manuel llevaba 2I años sin delinquir y Luis persistía en su carrera delictiva. Si bien existieron ligeras divergencias en su entorno social (Luis refirió el mantenimiento de amistades delictivas, mientras que Manuel explicó su abandono), entendemos que tales diferencias obedecen a la decisión de mantenerse en la persistencia criminal o a un esfuerzo por distanciarse de la misma, como otros estudios argumentan (p. ej., Giordano et al., 2002; Laub \& Sampson, 2003; Paternoster \& Bushway, 2009; Rocque, 2017; Sampson \& Laub, 2005).

\section{Instrumentos}

The Life Story Interview II (LSI-II) (McAdams, 2008). Se trata de un modelo de entrevista semiestructurada en la que el entrevistado ofrece un relato autobiográfico en el que diferencia diversos capítulos, atendiendo a su contenido. Su estructura permite la división en distintas secciones y temáticas para la posterior comparación del contenido, si bien el participante 
puede organizar su narración como estime oportuno. En esta investigación se procedió a una adaptación de la LSI, con el fin de adecuar la entrevista al estudio focalizado de la vida delictiva y la continuación o abandono del comportamiento criminal, así como a la experiencia de hallazgo de un sentido en la vida.

\section{Procedimiento}

Se contactó con los participantes por mediación de dos asociaciones ubicadas en Valencia (España) que trabajan con exconvictos y personas en situación de riesgo de exclusión: el Casal de la Pau, que facilitó las entrevistas con Manuel, y la Confraternidad Carcelaria de España, que facilitó las entrevistas con Luis. El Casal de la Pau garantizó la reinserción íntegra de Manuel, así como la ausencia de actividad delictiva durante los últimos $2 \mathrm{I}$ años. Las entrevistas fueron diseñadas y aplicadas por los autores del presente trabajo, sin que fuera necesaria la participación de otros profesionales. Asimismo, los análisis fueron hechos por los autores.

Con cada participante se realizaron un total de tres entrevistas individualizadas entre octubre de 2019 y marzo de 2020, con una duración aproximada de una hora y media cada una de ellas. Las entrevistas fueron grabadas y transcritas para proceder a su posterior análisis. Para cada participante se siguió el siguiente procedimiento: (I) primera entrevista: de carácter preliminar, dirigida a crear un clima de confianza y sinceridad con los participantes, $y$ en la que se les expuso la finalidad del proyecto y el carácter voluntario de su participación, y se firmó el consentimiento informado; (2) segunda sesión: se solicitó a los participantes que realizasen un relato libre sobre su historia de vida (historial familiar, escolar, laboral, etc.), con énfasis en su carrera delictiva, destacando los motivos por los que la iniciaron, sus experiencias de detención y encarcelación y posterior reincidencia; a tal efecto se siguió la estructura del modelo de entrevista semiestructurada del LSI (McAdams, 2008), adaptada para enfatizar la narración de la trayectoria criminal; (3) tercera entrevista: se abordaron cuestiones relativas a la vida actual de los participantes, el concepto que tenían sobre ellos mismos, cómo interpretaban su pasado y sus expectativas de futuro, así como el sentido de su vida.

\section{Análisis}

Se procedió a un análisis cualitativo del contenido de las entrevistas mediante categorías, desde una perspectiva tanto inductiva como deductiva (Bengtsson, 2016; Braun \& Clarke, 2006; Herzog, 2016). Esta investigación se centra en el análisis de componentes del sentido de vida de los participantes contenidos en sus relatos, siguiéndose las propuestas de George y Park (2016, 2017), quienes conciben el sentido de vida como aquel sentimiento en el cual un individuo "experimenta que su vida tiene sentido, que se encuentra dirigida y motivada por metas valiosas y que importa en el mundo" (George \& Park, 2016, p. 206). Los autores señalan que el sentido de vida se construye por tres dimensiones que pueden ser observadas a través de distintos indicadores: comprensión de la propia vida (sentimiento de coherencia y entendimiento sobre la vida de uno mismo), propósito en la vida (percepción de que la vida se encuentra dirigida y motivada por unas metas que el sujeto considera valiosas) y sentimiento de importancia (sentir la existencia de uno mismo como significativa y valiosa en el mundo) (Tabla I).

\section{Tabla I.}

\section{Categorías de sentido de vida e indicadores}

\begin{tabular}{|c|c|c|}
\hline Categoría & Indicador de presencia de sentido & $\begin{array}{l}\text { Indicador de ausencia de sentido } \\
\text { (vacío existencial) }\end{array}$ \\
\hline $\begin{array}{l}\text { Comprensión } \\
\text { de la propia vida }\end{array}$ & $\begin{array}{l}\text { Percepción de que la vida tiene sentido, } \\
\text { que los acontecimientos vividos parecen } \\
\text { claros y encajan entre sí. Sentimiento de } \\
\text { que las cosas son como deberían ser }\end{array}$ & $\begin{array}{l}\text { Se percibe la vida como incoherente, } \\
\text { fragmentada, poco clara e infeliz }\end{array}$ \\
\hline Propósito de vida & $\begin{array}{l}\text { Presencia de un claro sentido de dirección } \\
\text { en la vida, así como un fin hacia el que } \\
\text { se encamina Compromiso con la vida } \\
\text { y las metas personales que se fijan }\end{array}$ & $\begin{array}{l}\text { Experiencia de falta de dirección u objetivo } \\
\text { de su vida; nada de lo que se presenta } \\
\text { en su futuro parece valer la pena }\end{array}$ \\
\hline $\begin{array}{l}\text { Sentimiento de } \\
\text { importancia o } \\
\text { valía personal }\end{array}$ & $\begin{array}{l}\text { La persona siente que su vida influye sobre el } \\
\text { mundo y que sus acciones tienen consecuencias }\end{array}$ & $\begin{array}{l}\text { La existencia se percibe con una escasa relevancia } \\
\text { en el mundo; pensamiento de que su inexistencia } \\
\text { implicaría una escasa diferencia en el universo }\end{array}$ \\
\hline
\end{tabular}

Fuente: adaptada de George y Park (2016, p. 206). 
El proceso de análisis se estructuró en dos momentos: (I) análisis de la presencia o ausencia de un sentido en la vida (vacío existencial) y adopción de una perspectiva resiliente a lo largo de las distintas etapas de la vida de los participantes (pasado, presente y expectativas de futuro) e (2) identificación del modo en que los componentes del sentido de vida (presencia/ausencia) eran percibidos y valorados por los participantes, así como su posible relación con la persistencia/desistimiento de la carrera delictiva.

\section{Resultados}

\section{Relato de desistimiento (Manuel)}

Manuel atribuyó su temprano abuso de alcohol y anfetaminas (a los 12 años) a lo que podría calificarse como 'experiencia de vacío existencial', ya que era una forma de hacer frente a la insatisfacción por su estilo de vida solitario y a la falta de afecto. El consumo de estas sustancias, según refirió, le permitía desinhibirse, olvidar sus problemas existenciales e interactuar con otros grupos de jóvenes delincuentes, quienes estimularon el inicio de su comportamiento ilícito. Tales ideas coinciden con los hallazgos de Maruna (200l), quien observó en su trabajo que algunos participantes recurrían al abuso de drogas, a las actividades de riesgo o al delito como una forma de confrontar "un sentimiento de vacío".

Manuel: Cuando era más pequeño, cuando bebía, pensaba que no quería estar en esta vida, y por eso bebía [...] hacía locuras porque no quería estar en esta vida. Es como que estás en el mar y el mar te trae para la tierra y tú lo rechazas [...] Y mi forma de escapar de la vida era beber y estar en mi mundo, porque realmente no quería nada, no quería haber nacido [...] En cambio ahora no. Ahora sé que hago falta.

El entrevistado subrayó que su carrera delictiva estaba estrechamente ligada con su dependencia a la heroína (la cual inició a los 15 años). Si bien su familia intentó forzar su abandono del consumo, esto fue posible solo cuando encontró un "aliciente" para tal cambio a los 43 años, es decir, un propósito personal que le reportaba un sentimiento de bienestar que no había logrado experimentar durante su pasado delictivo y drogodependiente: la felicidad de ayudar a otras personas y el amor de su pareja.
En consecuencia, durante los últimos 21 años, Manuel ha participado como voluntario ayudando a la reinserción y desintoxicación de otros expresidiarios en el Casal de la Pau, asociación que le dio cobijo tras el cumplimiento de su última condena. Esto es convergente con los resultados de numerosos trabajos, que señalan que quienes desisten en su carrera delictiva acostumbran a construir una narración en la que refieren la adquisición de nuevos roles de liderazgo en grupos comunitarios, asociaciones voluntarias o en sus familias, los cuales les reportan una fuente de satisfacción personal que no habían logrado experimentar a lo largo de su comportamiento delictivo (p. ej., Cid \& Martí, 20ll; LeBel et al., 2008; Maruna, 200I).

Manuel: Fui a un centro [...] Pero realmente no te sales del centro curao' [...] Lo que de verdad me ha curao' es el hacer el bien, que me ha enganchao' el poder ayudar a personas. Me he superao' al tener a mi mujer, que sé que mi mujer, si no es conmigo no vive y si no es por ella, yo no soy nada.

Entrevistador: ¿Qué crees que fue lo importante para salir de la delincuencia y la droga?

Manuel: [...] Tener un aliciente más fuerte que todo eso [...] A mí me ha ayudao' el estar con gente que me ha necesitao' y he ayudao' [...] Pero tienes que averiguar lo que necesitas [...] A mí cuando me decían, "Joder, Manuel, es que estás hecho polvo, que tal", yo no me veía hecho polvo, yo me veía bien... ¡Y me estaba muriendo de tanto ponerme! ¿Y cómo lo aprendí? Porque a mí me han ayudao' y porque no quería morirme. ¡Porque vi una luz ahí! ¡Vi que podía seguir viviendo, pero no con la mierda, sino pudiendo ayudar a las personas y me veía feliz así!

Entrevistador: Entonces, tu luz fue...

Manuel: Ayudar a gente [...] Salir del 'mono' nosotros para ayudar a otras personas.

Manuel atribuyó su bienestar actual y la forma en la que consiguió alcanzar la felicidad (ayudar a otros) a su deseo de enmendar sus errores pasados: logró consolidar un relato de redención en el cual exhibía una comprensión coherente y congruente sobre su propia vida, en tanto que dotaba de un sentido a sus acciones delictivas pasadas como precursoras 
necesarias para su nuevo estilo de vida prosocial. Dicho de otro modo, la actual identidad prosocial que había logrado desarrollar encajaba con su pasado delictivo. Esta perspectiva resiliente, consistente en reinterpretar los errores y el sufrimiento pasado como parte del proceso de mejora y crecimiento personal, se corresponde con la actitud propia del 'optimismo trágico' (Frankl, 2004).

Entrevistador: ¿Cómo te ha afectado esto en la persona que ahora eres?

Manuel: [...] Mucho [...] Creo que le estoy haciendo el bien a la gente por taparme el mal que hice ese día [refiere su último delito, en el que casi mató a un amigo suyo].

Entrevistador: ¿Tú crees que es por eso?

Manuel: [...] Yo, querer quitarle la vida a ese chaval, no lo quería. Y si ahora estoy haciendo las cosas bien es por tapar eso [...] Eso no se te puede olvidar jamás, a nadie, que tenga un poco de... Y quiero tapar ese mal y eso [...] Quiero llegar a pagarlo.

Entrevistador: Imagínate que tienes aquí el libro de toda tu vida ¿de qué dirías que va el libro?

Manuel: [...] Vivir una vida nueva [...] Una vida vieja y una vida nueva, el capítulo de una vida nueva y una vida vieja [...] Aquí está la vivencia de una persona vieja y una persona nueva (...) Una vida mala y una vida buena, he empezao' por la mala y acabao' con la buena. La buena, que he lograo' gracias a que me di cuenta de mi felicidad, y de ayudar a los demás.

Se describió como feliz con su actual estilo de vida gracias a la presencia de múltiples fuentes de sentido que había adquirido desde que cesó en la delincuencia. Debido a su avanzada edad (64 años), señaló que actualmente no tenía grandes metas avariciosas, si bien destacó que gozaba de múltiples propósitos de vida que le estimulaban a seguir adelante y a luchar contra las dificultades de su estado de salud (enfermo de Sida y bajo tratamiento de diálisis): continuar apoyando a su mujer y a su hija, así como disfrutar de la vida y ayudar a los demás.

Asimismo, hizo una distinción entre el sentido que tenía su 'yo actual' y su 'yo pasado': durante su carrera delictiva siempre experimentó un gran malestar y sentía que su existencia carecía de propósitos, ilusiones o motivación alguna, más allá de la de lograr obtener dinero para poder costear su consumo, lo que le condujo a múltiples tentativas de suicidio por sobredosis.

Entrevistador: ¿Qué es lo que da hoy en día sentido a tu vida?

Manuel: [...] Ahora tengo un sentido de querer vivir [...] y seguir conociendo cosas [...] Lo que antes no lo tenía, no lo veía, yo me quería morir. Ahora pues sí, eso le veo sentido. No quererme morir de aquí a mucho tiempo pa' ir siguiendo el transcurso de la vida cómo va y... Y a lo mejor poder aportar algo de lo que yo sepa. Si yo perdiese ahora la vida... No haría yo todo lo que quiero hacer y lo que yo quisiera ver. Si yo me muero no veo crecer a mi hija y tener su carrera, tener sus hijos y eso. Estar con mi mujer... con ella. Si yo me muero, sé que se moriría mi mujer también. Si se muere mi mujer... ¡Qué sería yo de mí! Hay cosas que me unen ya más que antes, porque ahora me encuentro bien, no me hace falta una sobredosis, no me hace falta nada. Me hace falta ver a mi mujer, que mañana vaya a casa y encontrármela y dormir junto con ella y verla feliz. Bien. Eso es lo que me da la vida. ¿Y pa' qué me quiero morir? Pues no, ara' no. Y le pido a Dios que no me lleve.

Entrevistador: ¿Cómo te imaginas el futuro que tú quieres ver?

Manuel: [...] Ver a mi hija con niños y que... Estar yo en el banco, con mi mujer, con el bastón, cogidos de la mano y mis nietos.

Entrevistador: ¿Este futuro que tú ahora te imaginas, es el mismo que te imaginabas en el pasado?

Manuel: [...] En el pasado yo no me imaginaba ningún futuro. Yo estaba ahí como el que está... Más perdido que [...] De la manera que estaba, no tenía sentimiento ninguno [...] No era persona, no era persona ni era nada, porque ni tenía fines ni tenía grandezas, ni tenía una meta, ni tenía nada, no era nada. Un tío que no tenía ilusiones de nada. [...] Estaba muerto en vivo, porque las cosas bonitas de la vida me las estaba perdiendo [...] Lo único que me interesaba era ponerme para quitarme el mal que tenía y que fuese tirando [...] Ni era feliz ni desfeliz [...] Estaba en un mundo que no era real y ahora he 
despertao' [...] En ese mundo es que no sientes ni padeces, estás dormido.

Manuel verbalizó una visión optimista de futuro, de manera que se sintió prácticamente incapaz de imaginarse recayendo en el consumo de sustancias o en la conducta delictiva. En consonancia con otros estudios (p. ej., Doekhie et al., 2017; King, 20I3; Souza et al., 2013), dicha forma de concebir su desarrollo personal se relaciona estrechamente con el desistimiento y el pronóstico de reinserción.

De manera más específica, señaló que sus propósitos de vida no solo contribuían a su bienestar actual, sino que además le habían ayudado durante más de dos décadas a prevenir la reincidencia y el consumo de estupefacientes; por el contrario, observó que perderlos promovería su recaída. En términos criminológicos, se podría decir que estas fuentes de sentido, y los propósitos vitales que de ellas derivan, han actuado en Manuel como factores de protección, en tanto que lo distanciaron del consumo de estupefacientes y la actividad delictiva; el malestar ocasionado por su ausencia o desaparición, por el contrario, podría actuar como factor de riesgo y estimular la reincidencia.

Entrevistador: ¿Te imaginas delinquiendo en el futuro? Manuel: Prefiero morirme a llegar a ponerme heroína o a delinquir o a lo que sea [...] Si no quiero morirme es porque tengo a mi mujer y porque me he quitao' de toa' esta mierda y quiero vivir pa' ver a mi hija cómo se desarrolla en esta vida. ¿Y yo, por qué yo no me he ido? [...] Porque hay algo [...] Porque ayudando salgo bien, que a lo mejor si no tuviese na' que hacer pues a lo mejor ya me habría muerto o seguiría enganchado o robando.

Entrevistador: ¿Tú crees que si no tuvieras ese propósito...?

Manuel: ¡No tendría nada! ¡No tendría sentido mi vida! ¡Yo seguiría en las mismas! [...] Yo ya hoy en día vivo con una persona que me necesita y ella me necesita a mí y yo a ella y por eso estamos viviendo.

Entrevistador: ¿Qué crees que pasaría si no tuvieses nada?

Manuel: [...] Me volvería loco o estaría con una botella en la calle o yo qué sé. Pero no estaría como estaría ahora.
Con respecto al sentimiento de importancia o valía personal, explicó que actualmente percibía su vida y sus actos como valiosos para otras personas (especialmente para su esposa, a quien cuida, y para aquellos a los que ayuda, como ya se señaló). Más concretamente, destacó que incluso su participación en la entrevista supuso una oportunidad de demostrar su valía personal, ya que sentía que con ello ayudaba al avance del conocimiento para el auxilio de otras personas que aún estaban delinquiendo.

En contraposición, subrayó que en su pasado su vida no solo no era valiosa o importante para el mundo, ya que (vista en perspectiva) era dañina, pues sus actos delictivos perturbaban el bienestar de otros.

Entrevistador: ¿Crees que tu existencia y las cosas que tú haces son importantes para otras personas?

Manuel: Creo que sí [...] Si no, no las haría [...] Hablar contigo ya es importante, pa' otras personas y pa' mí mismo, porque me estoy desahogando y recordando cosas y a lo mejor en un momento se me hubiesen olvidao' y a lo mejor...

Entrevistador: ¿Crees que esto también era así en tu pasado cuando delinquías? ¿Crees que tu vida era importante para otras personas?

Manuel: ¡Qué va! [...] No era importante, era peor [...] Mi vida era mala, porque lo que hacía era el mal. Robaba, mentía, si iba contigo era por algo, pa' ver si te podía quitar algo.

\section{Relato de persistencia (Luis)}

Luis relató que llevaba fuera de prisión desde julio de 2019. Si bien se presentó a sí mismo como una persona cambiada desde el cumplimiento de su última condena (refiere que ha abandonado su conducta delictiva y toxicómana), su narración fue ambigua, pues reconoció un consumo puntual de cocaína y tráfico de pequeñas cantidades de droga, así como la comisión de hurtos (conductas que minimizó y no definió como delitos). Tal ambivalencia en el discurso (distanciamiento de la identidad delictiva, a pesar de la persistencia en la actividad ilícita) es un fenómeno que se observa en estudios previos sobre relatos de delincuentes persistentes (p. ej., Cid \& Martí, 20ll; Doekhie et al., 2017; Martens, 2017).

Destacó que su entorno social se componía principalmente de sus antiguas amistades delictivas 
y su pareja (consumidora de cocaína), a quienes responsabilizó de su incapacidad para cambiar y abandonar de forma plena el abuso del alcohol y cocaína, ya que ellos lo estimulaban. Asimismo, verbalizó un pronóstico negativo de su futuro, en tanto que reconoció la alta probabilidad de mantener tal conducta ilícita, lo cual atribuyó a su situación de precariedad económica y a las dificultades "del sistema". Este tipo de justificaciones, que no reconocen la responsabilidad personal para el cambio (Frankl, 2004), son frecuentes en los relatos de quienes mantienen la carrera delictiva (p. ej., Doekhie et al., 20I7; Maruna, 200I).

Luis: Estoy inseguro [...] Tengo la certeza de que va a ir mal.

Entrevistador: ¿Por qué piensas eso?

Luis: Porque lo tengo a la vista... Me lo huelo [...] Yo en mí sí que confío, sé lo que quiero y tal. En quien no confío es en los otros. $Y$ que tenga que hacer unas cosas u otras... es difícil.

Entrevistador: ¿Cómo crees que va a ir mal?

Luis: Porque la gente no tiene la convicción que tengo yo [...] ¡Y es que encima me culpan a mí! Si lo que quieren es que vaya yo de cabeza. Llego a las cinco de la mañana y me ofrecen la mierda esa... ¿Esto es lo que tú quieres pa’ mí? 'Enga, pues trae pacá'.

Entrevistador: ¿Cómo te imaginas en tu futuro? ¿Te imaginas delinquiendo?

Luis: Yo con levantarme, seguir vivo y no volver a ir a la cárcel me conformo [...]. No me gustaría volver a delinquir, pero si tengo que hacerlo, lo haré. $Y$ escúchame, lo siento, pero sé que lo haré. $Y$ no quiero.

Entrevistador: ¿Por qué lo crees?

Luis: Porque a veces, la necesidad... Que no me dé para comer, para beber [...] No me gustaría, pero bueno. A ver, que robar para comer no es delinquir... Es que es complicao'. A ver, dime tú: ¿cómo aguanto hoy en día con 400 al mes? La luz, el alquiler, el agua y comer. ¿Y cómo lo hago, pa' pagarlo? ¿Cómo ando? Ese es el problema. El sistema.
A lo largo de su narración, verbalizó en repetidas ocasiones una falta de felicidad en su vida y nihilismo existencial, es decir, un pensamiento de que su existencia carecía de un objetivo, propósito o valor intrínseco (Frankl, 2004), explicando que su único sentido de vida era "continuar su día a día hasta alcanzar la muerte". Este estado de vacío existencial no solo quedó reflejado en sus declaraciones sobre su manera de entender la vida, sino que también condicionó la manera en la que explicó el desarrollo de su vida cotidiana: refirió un gran esfuerzo para evitar salir de casa (incluso de la cama), así como un abuso reiterado de alcohol como recurso para afrontar sus pensamientos y estado emocional negativo (de la misma forma que lo hacía Manuel durante su persistencia delictiva). En consecuencia, explicó que en ocasiones nada de lo que le deparaba su vida era lo suficientemente estimulante como para que se decidiera a abandonar su rutina delictiva $o$ proponerse nuevas metas.

Entrevistador: Vamos a hablar ahora acerca de tu sentido de vida. A medida que uno crece se da cuenta de tiene que vivir para algo...

Luis: Yo vivo para morirme [...] Desde que nací [...] He sabío que yo he nacío' pa' morirme [...] desde jovencito, yo dije "yo he nacío pa' esto" [...] Yo sé que estoy aquí pa' irme [...] Mi vida hoy en día es el día a día también... Y hay días que me pesan más que otros, $y$ estoy en casa.

Entrevistador: ¿Cómo te sientes en tu día a día?

Luis: [...] A veces es que ni me siento [...] me levanto por la mañana y no quiero ni salir de la cama [...] No sé, mi vida no es ni pena ni alegría [...] No tienes ilusión, no tienes alicientes [...] Y me pongo: cinco, seis, siete cervezas [...] Si es que la vida es eso, pues el día a día, la rutina. Es monótona. Es una mentira. Es mantenerte engañao'.

Entrevistador: Entonces, ¿tú cuál crees que es tu sentido de vida?

Luis: Pues mi sentido de vida es seguir viviendo [...] $Y$ por el camino intentar no meterte mucha mierda de esta [...] Ser conformista. Eso sí, a trabajar no vayas [...] Porque vas a trabajar como un burro y vas a ganar poco [...] Creo que el mayor desafío de 
mi vida es enfrentarme al día a día [...] levantarte y un día y decir que estás ahí. $Y$ punto, y nada más.

Entrevistador: ¿Tienes ilusiones o alicientes?

Luis: No, no [...] la visión que a mí me viene de trabajar es ipara qué? [...] Luego que si te van a dar 800 por todo y yo tengo por aquí pues que me puedo sacar 400 estando en casa [...] ¿Pa' que voy a ir a trabajar por 800 o 900 pavos? [...] En mi casa y estoy tranquilo [...] no tengo que ir a robá' por ahí. De momento, ya veremos.

Entrevistador: ¿Tú crees que eres feliz?

Luis: La felicidad no existe. La felicidad es una sensación pasajera, es como el amor, es pasajera. Si no... Pero ya te digo yo, la felicidad es un momento [...] Pero la felicidad yo creo que es un estado de ánimo que una persona solo tiene en unos pocos momentos de su vida [...] Que ojalá fuera todos los días igual... Pero no es así.

Tal ausencia de sentido de vida también pudo apreciarse en su falta de propósitos o metas que orientasen su día a día, más allá de la inercia cotidiana, que lo hiciesen sentirse comprometido con su presunta voluntad de distanciarse de la delincuencia. Si bien observó que en su pasado tuvo algunos proyectos, responsabilizó de su abandono a las dificultades y los obstáculos planteados por "los políticos" y el "sistema", los cuales erigieron barreras que le imposibilitaron cumplirlos (negación de la propia responsabilidad; cfr. Frankl, 2004).

En consonancia con estos hallazgos, Maruna (200I) observó en su estudio que quienes persistían en la delincuencia mostraban un relato carente de objetivos diarios o cotidianos, lo que acuñó como una narrativa de estilo pasivo ("narrativa pasiva"). De acuerdo con este autor, tales declaraciones se caracterizaban por la exposición de unas metas de futuro no respaldadas por acciones específicas o logros a corto plazo. En consecuencia, muchos de los participantes en su estudio referían propósitos personales idílicos (p. ej., ganar la lotería), no sujetos a cambios en su actitud o conducta. Esta también fue una de las respuestas ofrecidas por Luis.

Entrevistador: ¿Tienes algún sueño, algún propósito? ¿Algo que te gustaría cumplir en tu vida?
Luis: ¿Hoy en día? [...] Solo tengo ilusión de levantarme mañana de que [...] hay veces que me gustaría despertarme después de tres días, porque es que es siempre lo mismo [...] Con levantarme y estar ahí me conformo. Si no, pues malo. Eso es ya lo único que deseo.

Entrevistador: ¿Y alguna meta personal? ¿Un proyecto de vida?

Luis: Pues seguir pa' adelante y poco más... Yo tenía un propósito antes, cuando salí [de prisión]: ser autónomo, pagar mis impuestos y tal [...] De hacer algo, no acabar como estoy ahora, que tengo casi 55 años [...] Pero ahora se han juntado los políticos y todo esto, los que tienen poder y yo no puedo... Así que yo ya no quiero na'. Como no han podío' ellos ayudarme... ¿Te vas a hacer autónomo y me tengo que pagar la cuota de 3000 ? Pues tira... ¿Qué quieres, que los pinte o algo? Pues paso [...] Me quedo en casa.

Entrevistador: ¿Entonces, crees que has perdido este proyecto porque...?

Luis: Porque no me quieren ayudar. Los políticos, no me quieren ayudar. Me hicieron estudiar allí [en la cárcel], sacarme un título y luego pa' na' [...] paso, que no quiero que me engañen [...] El sistema no funciona, no me echa una mano... No me dan la posibilidad [...] Pues no voy a trabajar más. ¿No quieren ellos? Pues yo tampoco.

Entrevistador: ¿Hay algo que te gustaría cambiar en tu vida? ¿Querrías haber logrado algo?

Luis: ¿Esto es una pregunta trampa? Está claro: me gustaría que me hubiera tocao' la lotería [...] porque la primitiva no estaba en mi pasado [ríe]. Es lo único que me gustaría cambiar de mi vida [...] no me hubieran hecho falta toas' estas cosas que hago ahora.

Con respecto a la comprensión sobre el sentido de vida, el relato de Luis dejó entrever en múltiples ocasiones incoherencias o ambivalencias, reconociendo él mismo que en ocasiones se comportaba de manera errática y confusa. Llegó a expresar que a veces sentía su propia vida como una mentira, lo cual le llevaba a recurrir al alcohol, a fin de 
evitar pensar demasiado en sus problemas, en cómo se sentía y en la visión que tenía sobre sí mismo. Más aún, se confesó incapaz de entender su propia historia y que él mismo no la recomendaría a nadie que la conociese.

Entrevistador: Imagínate que escribes un libro acerca de toda tu vida [...].

Luis: No se lo recomendaría a nadie.

Entrevistador: ¿Por qué?

Luis: [...] No sería una buena historia [...] No tiene ni pies ni cabeza, es una historia triste [...] No se lo deseo a nadie, ni como castigo... Ni como la peor condena.

Entrevistador: Entonces, ¿si tuvieras que decirle a alguien de qué trata tu vida, de qué va el libro de tu vida?

Luis: Trata de mi día a día [silencio prolongado]. No lo entendería [...] Nadie va a entender mi vida... ¡A veces ni yo mismo la entiendo! Nadie se va a poder poner en mi lugar, ni yo me voy a poder poner en su lugar [...] Tu vida solo la has pasao' tú, nadie lo va a entender. Ni yo mismo. No se lo deseo a nadie.

Entrevistador: ¿Cómo lidias con tu día a día?

Luis: Me levanto... Espero que se haga de noche para volver a acostarme y levantarme al día siguiente. ¿Enfrentarme al día a día? A veces no salgo de casa... O me tomo dos o tres copas. No sé, tampoco es que me pase, pero... Me bloqueo. Adrián, me bloqueo... Y ¡Pam! Me tomo otras dos copas y me acuesto. Y... Si vas pa' acá' mal, si vas pa' allá pues peor. Ya... Pues mejor no salgo, no hago nada. Me bloqueo, me bloqueo. Me encierro solo en casa a beber. No me hace falta irme a ningún lao', cuatro o cinco y a dormir. Que no voy a salir por ahí. Mejor me quedo en casa, conmigo mismo y prefiero luchar en mi guerra que en la batalla de los demás [...].

Entrevistador: ¿Y cuál es tu guerra?

Luis: Mi guerra es el día a día, lo que tú me has preguntado. Llegar a mañana. Aunque hubo días que me daba igual. Ya ni me levantaba, me importaba un carajo to', no valía na' la pena...
Entrevistador: ¿Y cómo crees que ha cambiado eso?

Luis: Eso no ha cambiao', eso ha estao' siempre ahí... Es lo que intento explicarte, que eso no ha cambiao', eso siempre ha estao', coño [...] Pa' mí que el gilipollas soy yo. Que no tienes necesidad de estar ahí y aún estás ahí... Tantos años... Y eso me duele en el alma.

Entrevistador: ¿Qué significado tiene esto para ti en tu vida?

Luis: Yo pa' mí que soy yo el problema. Yo creo que el problema he sío' yo'... Porque estás ahí y ya el problema... El problema no es la familia que no me apoya, que no está ahí, que tal, que cual... El problema creo que soy yo... Y ya, hasta llegar ahí, es muy difícil... El problema soy yo. El día a día está difícil y cada vez peor.

En cuanto al sentimiento de importancia o valía personal, Luis concibió su existencia con un escaso significado, de modo que consideró poco importante para los que le rodeaban y manifestó que, en muchas ocasiones, él mismo se había planteado esa cuestión. Al igual que ocurre con las referencias de Manuel a su pasado delictivo, Luis reconoció que tal autopercepción se derivaba del malestar que cree que ocasionaba en su entorno a través de su comportamiento volátil y conflictivo, así como de su autoconcepto como persona de trato difícil. Pensó que su desaparición podría ayudar a que terminasen los problemas de los que le rodean; según refirió, tal sentimiento de falta valía personal persistió en su vida por largo tiempo, en tanto que también lo tuvo en su pasado.

Entrevistador: ¿Crees que hoy en día tu vida es importante para los demás?

Luis: Para nadie [...] Como mucho pa' mi madre, que está a mi lao' y a veces incluso dudo de que lo sea [...] Siempre o lo he dudao' yo, que mi vida es importante, o lo ha dudao' el que está a mi lao'... No lo sé por qué [...] Me lo he preguntao' muchas veces y tampoco sé por qué.

Entrevistador: ¿Por qué piensas que no lo es?

Luis: Para los demás dudo de que sea importante $[. .$.$] porque me he dao' cuenta de que ya han$ 
llegao' a su límite [...] ya no me aguantan [...] porque si no estoy yo, ya no habrán problemas para nadie [...] Soy una persona muy difícil, que llego, que cojo, que tal, que me pongo nervioso [...] Muy difícil de tratar para mis seres queridos. Ya para los demás ni te digo, pero me da igual. Entrevistador: ¿Por qué crees que eres difícil de tratar, muy complicado?

Luis: [...] Porque solo traigo malestar a mi familia [...] me pongo nervioso rápido y me pierdo [...] cada uno va a su ritmo y yo [...] soy difícil y choco con todos. A veces llego y me veo fuera de lugar. Me siento fuera de lugar.

Entrevistador: ¿Crees que en tu pasado tu vida era importante para los demás?

Luis: Nunca he sido importante para los demás, Adrián. He estao' ahí, he ayudao', pero en mi vida, importante [...] Creo que alguna vez, en mi vida, algunas personas me apreciaban. Pero importante, no creo. Fui importante [...] para mi mujer, y [...] la defraudé... En el pasado la defraudé... Me jode.

\section{Discusión}

El objetivo de este estudio consistió en el análisis de los relatos de dos varones españoles con características sociodemográficas y carreras delictivas similares, si bien uno de ellos hacía 2 I años que había desistido (Manuel) y el otro persistía en su actividad ilícita (Luis). El propósito fue identificar elementos que indicasen la presencia o ausencia de sentido de vida. Se hipotetizó que el caso de desistimiento incluiría en el relato elementos de comprensión sobre la propia vida, propósitos vitales y sentimiento de valía, mientras que en el caso de persistencia estarían ausentes (vacío existencial).

Los resultados obtenidos confirmaron la hipótesis: en el caso de Manuel, su narración reveló elementos de presencia de sentido de vida que podrían haber facilitado su proceso de desistimiento; por el contrario, en sus referencias a su "yo pasado" (delictivo), tales aspectos acusaban ausencia. En el caso de Luis, que persistía en la conducta delictiva, los elementos de vacío existencial se revelaron actuales y podrían estar contribuyendo a la persistencia de la carrera delictiva.
El relato de desistimiento de Manuel puso de manifiesto algunos elementos directamente relacionados con los que la logoterapia señala como característicos de presencia de sentido (Frankl, 2004): necesidad de, y determinación para, encontrar un sentido de la vida (motivo fundamental, de orden existencial); conciencia de la capacidad de autodeterminación más allá de los condicionantes biopsicosociales (libertad de la voluntad); asunción de la responsabilidad personal (responsabilidad); superación de la "ceguera de valores" (Lukas, 2002) y percepción de aspectos significativos en la existencia personal por los que merece la pena cambiar (autotrascendencia); perspectiva existencial no dominada por la búsqueda de gratificación (voluntad de placer; p. ej., consumiendo sustancias) y dominio (voluntad de poder; p. ej., dominio sobre los demás mediante la delincuencia), sino por la búsqueda de un sentido auténtico, existencialmente positivo (voluntad de sentido); identificación del sentido de la vida en las circunstancias personales que reclaman compromiso (pareja, hijos, trabajo, entre otros); conciencia de que tal compromiso solo puede ser asumido personalmente; establecimiento de metas y objetivos significativos; optimismo, entre otros. Estos elementos, precisamente, estaban ausentes en la narrativa de Luis, que contenía, más bien, rasgos característicos de vacío existencial, opuestos a los señalados en el caso de Manuel.

En ambos participantes, la ausencia de un sentido de vida positivo y constructivo (en el caso de Manuel, durante su pasado delictivo; en el caso de Luis, persistiendo en la actualidad) se reveló en el abuso de alcohol, autoconcepto negativo y baja autoestima, negación de la responsabilidad personal y atribuciones externalistas, ausencia de metas vitales significativas e incapacidad para percibir el valor y dignidad de aquellos a quienes se dañaba con el consumo de drogas y la conducta delictiva.

Debe indicarse, al respecto, que el abuso de alcohol y la participación en actividades ilícitas (comportamiento delictivo como forma de búsqueda de adrenalina) constituyen estrategias (erróneas) empleadas para obtener un bienestar temporal con el que confrontar su ausencia de sentido de vida: la falta de propósitos de vida y de percepción de valía existencial podrían predisponer a una actitud nihilista ante la vida que estimulase la búsqueda de cualquier forma de gratificación superficial como forma de evitar la experiencia de vacío. Por el contrario, un sentido de vida pleno, en sus diferentes expresiones, 
podría constituir un factor de protección que activase y mantuviese el relato de desistimiento: la experiencia de que la propia existencia resulta importante para otras personas y el compromiso con determinados propósitos de vida consolidarían una nueva identidad narrativa espiritualmente satisfecha (frente al vacío existencial pasado) que inhibiese la comisión del comportamiento delictivo. El sentimiento de autorrealización experimentado por el sujeto ( $y$ el bienestar que del mismo se derivaría) prevendría la reincidencia, ya que la misma implicaría un distanciamiento de tales fuentes de sentido adquiridas. Estas ideas coinciden con los fundamentos de múltiples teorías criminológicas (p. ej., Giordano et al., 2002, 2007; Laub \& Sampson, 2003; Paternoster \& Bushway, 2009; Sampson \& Laub, 1993, 2005).

La presencia o ausencia de sentido de vida no sería capaz de explicar, por sí sola, el inicio, persistencia o desistimiento de la carrera delictiva, ya que existen otras muchas variables implicadas en su desarrollo: como ha destacado la literatura, la evolución de la trayectoria criminal (y su fin) resulta de la confluencia de múltiples condicionantes personales, sociales y ambientales (apoyo percibido, entorno convencional o delictivo, existencia o no de estresores, etc.) (p. ej., Agnew, 2009; Cid \& Martí, 201l; Laub \& Sampson, 2003; Sampson \& Laub, 1993; Redondo, 2017), así como de la valoración e interpretación que los sujetos realizan sobre los mismos de acuerdo con su motivación personal y su identidad construida (p. ej., Giordano et al., 2002, 2007; Maruna, 200I; Paternoster \& Bushway, 2009; Rocque, 2017; Sampson \& Laub, 2005). Atendiendo al caso particular, algunas de estas dimensiones pueden desempeñar un rol más determinante, tanto para el inicio y la persistencia, como para el desistimiento, mientras que otras tal vez desempeñen un carácter más secundario (Redondo, 2017; Redondo \& Garrido, 2013; Sweeten \& Khade, 2018). En relación con el desistimiento, algunas quizá sean incluso las desencadenantes de la percepción de necesidad de dar un 'giro copernicano existencial' y activen un sentido de vida que desencadene el proceso de abandono de la carrera delictiva (p. ej., la religión, la experiencia de paternidad, la participación en un grupo o asociación, entre otros). Además, considerando que el desistimiento es un proceso y no un fenómeno dicotómico de 'todo o nada' (Gadd \& Farrall, 2004; Kazemian \& Maruna, 2009; Liem \& Richardson, 2014; Redondo, 2017), la relevancia relativa de tales variables puede cambiar a lo largo del tiempo, pudiendo algunas ser más relevantes al inicio y otras posteriormente.
Por tanto, en el caso de los participantes en el presente estudio, entendemos que los elementos relativos al vacío existencial/presencia de sentido de la vida que han aportado en sus relatos no son los únicos implicados en el desistimiento (caso de Manuel) o la persistencia de la conducta delictiva (caso de Luis): existen otras variables en las que ambos sujetos se diferencian y que pueden haber favorecido su (dis)continuidad criminal. A modo de ejemplo, Luis mantiene el contacto con sus amistades delictivas y drogodependientes (entre las que se incluye su pareja actual) y mantiene su abuso de alcohol y estupefacientes, los cuales constituyen factores de riesgo estrechamente asociados con la persistencia delictiva (p. ej., Redondo, 2017; Redondo \& Garrido, 2013; Thornberry et al., 20I3). En contraste, Manuel se ha distanciado de su entorno delictivo (si bien continúa ayudando a gente en situación de riesgo), tiene una hija y en la actualidad no consume ninguna clase de sustancia (incluyendo al alcohol); todos ellos son aspectos ligados al cese de la trayectoria ilícita, de acuerdo con la literatura (p. ej., Akers, 20 I I; Redondo \& Garrido, 2013; Sweeten \& Khade, 2018; Thornberry et al., 20l3). Numerosos trabajos también señalan que el envejecimiento se vincula a la finalización de la actividad criminal (p. ej., Gottfredson \& Hirschi, 1990; Hirschi \& Gottfredson, 1983; Moffitt, 1993; Redondo \& Garrido, 2013), si bien en el presente estudio las divergencias entre ambos participantes no parecen obedecer a la influencia de tal variable: Manuel cesó en la delincuencia hace 21 años, poco después de cumplir su última condena (refirió que con 43 años, aproximadamente); por el contrario, Luis persiste en la actualidad (con 54 años).

Los resultados del presente trabajo, junto con los de otros previos (p. ej., Black \& Gregson, 1973; Maruna, 200I; Eryilmaz, 20l8), aportan evidencia de que, como señalara Frankl (2004), la violencia (como lo es la conducta delictiva), el consumo de drogas y un estado de ánimo deprimido son expresión de vacío existencial. En consecuencia, se sugiere la conveniencia de tener en cuenta la presencia o ausencia de sentido de la vida en personas con carrera delictiva, tanto para la comprensión de los inicios y persistencia de la misma (con lo que los conocimientos al respecto en el ámbito de la criminología se verían sustancialmente enriquecidos), como para optimizar la intervención en esta población en aras de facilitar el proceso de desistimiento.

De igual manera, Frankl afirmaba que "los esfuerzos de rehabilitación de pacientes delincuentes o drogadictos son más positivos cuando afrontan 
la problemática del sentido de la vida" (2000, p. 7I), y aducía evidencia terapéutica (p. ej., Barber \& Fraiser, 1979). Estudios empíricos más recientes avalan la eficacia de una intervención centrada en el sentido para tratar la conducta criminal (p. ej., Day \& Ward, 20I0; McNeill, 2006; McNeill et al., 20I2; Ronel \& Elisha, 20II). Asimismo, diversos estudios criminológicos sobre el desistimiento y el pronóstico de reinserción han obtenido resultados que pueden estar ligados al sentido de vida: el cumplimiento de metas personales y el sentimiento de autorrealización asociado a ello (p. ej., Cid \& Martí, 2012; LeBel et al., 2008; Maruna, 200I; Ward \& Maruna, 2007), la capacidad de comprender y construir un relato coherente sobre la propia vida (p. ej., Bove \& Tryon, 2018; Maruna, 200I), la esperanza, la resiliencia y la redención (p. ej., LeBel et al., 2008; Maruna, 200I; Maruna et al., 2006; Stone, 20l6) y la adquisición de nuevos roles que reportan bienestar personal (p. ej., Cid \& Martí, 20I I; Giordano et al., 2002; LeBel et al., 2008; Sweeten \& Khade, 2018).

Sin embargo, el estudio específico del sentido de vida en el cese de la delincuencia es prácticamente inexistente en la literatura criminológica. Sería interesante estimular el desarrollo de una criminología centrada en el sentido (meaning-centered criminology) desde la que se aportaran recursos terapéuticos para la prevención y el desistimiento de la carrera delictiva. Los actuales programas a tales efectos en el ámbito criminológico podrían beneficiarse de las aportaciones de tal modelo, de manera que se pudiera favorecer el desarrollo de nuevas narrativas, marcadas por una actitud resiliente $y$ un sentido existencial que permitiera evitar o abandonar la carrera delictiva. En esta línea, la literatura ha demostrado la eficacia de una intervención focalizada en la reconstrucción de los relatos de vida, en la cual se auxilie al participante a alcanzar la comprensión y reinterpretación sobre la propia existencia y se favorezca la creación de una nueva identidad narrativa resiliente dirigida a la consecución de propósitos de vida positivos (p. ej., Bove \& Tryon, 2018; Ward, 2007; Ward et al., 2012).

Por último, el estímulo del sentido de vida en las narrativas personales podría reportar no solo múltiples beneficios para el tratamiento de individuos que ya han delinquido (prevención terciaria), sino que podría ser también de gran utilidad para la población en riesgo de conducta ilícita (prevención primera o secundaria), ya que su potenciación actuaría como un factor de protección que mitigaría la influencia de otros factores criminógenos. En este sentido, las intervenciones orientadas al desistimiento de la conducta delictiva podrían verse fortalecidas mediante el uso terapéutico de los relatos de vida, si se incluyeran en las entrevistas elementos que motivaran, por ejemplo, para la toma de conciencia del mal ocasionado (tanto a uno mismo como a los demás, con la conducta delictiva) y la responsabilidad personal ante ello y en relación con un cambio de vida, de la posibilidad de tomar las riendas sobre la propia vida (libertad de la voluntad, autodeterminación), del valor y dignidad de uno mismo y de los demás, etc. Las entrevistas podrían ser el contexto propicio en el que aplicar el método del diálogo socrático, recurso logoterapéutico indicado para el cambio de actitud existencial (cfr. Martínez, 2009) (si bien común a otro tipo de intervenciones, como la reestructuración cognitiva; cfr. Emmelkamp \& Vedel, 2006) y que se ha mostrado terapéuticamente eficaz para el tratamiento de la drogodependencia, trastornos mentales y trastornos de la conducta (p. ej., Martínez \& Flórez, 20I5).

\section{Referencias}

Addad, M., \& Himi, H. (20I3). Crime in the absence of meaning in life. International Forum for Logotherapy, 36(2), 72-76.

Agnew, R. (1992). Foundation for a general strain theory of crime and delinquency. Criminology, 30, 47-87.

Agnew, R. (2009). General strain theory. En M. D. Krohn, A. J. Lizotte \& G. P. Hall (eds.), Handbook on Crime and Deviance (Pp. 169224). Springer.

Akers, R. L. (20I I). Social Learning and Social Structure: A General Theory of Crime and Deviance. Transaction.

Andrews, D. A., \& Bonta, J. (2016). The Psychology of Criminal Conduct (6 ${ }^{\mathrm{a}}$ ed.). Routledge.

Barber, L. S., \& Fraiser, A. R. (1979). Juvenile delinquents. En F. B. Fabry, R. P. Bulka \& W. S. Sahakian (eds.), Logotherapy in Action (pp. 213-224). Jason Aronson.

Black, W. A. M., \& Gregson, R. A. M. (1973). Time perspective, purpose in life, extraversion and neuroticism in New Zealand prisoners. British Journal of Social and Clinical Psychology, I 2 (I), 5060. http://doi.org//0.1 I I I/j.2044-8260.1973. tb00845.x

Bengtsson, M. (2016). How to plan and perform a qualitative study using content analysis. NursingPlus Open, 2, 8-14. https://doi. org/10.1016/j.npls.2016.01.001 
Bove, A., \& Tryon, R. (2018). The power of storytelling: the experiences of incarcerated women sharing their stories. International Journal of Offender Therapy and Comparative Criminology, 62(15), https://doi.org/I0.1177/ $0306624 \times 18785100$

Braun, V., \& Clarke, V. (2006). Using thematic analysis in psychology. Qualitative Research in Psychology, 3, 77-101. https://doi. org//0.1191//478088706qp063oa

Cid, J., \& Martí, J. (20I I). El proceso de desistimiento de las personas encarceladas. Obstáculos y apoyos. Centro de Estudios Jurídicos y Formación Especializada.

Cid, J., \& Martí, J. (20I2). Turning points and returning points: understanding the role of family ties in the process of desistance. European Journal of Criminology, 9(6), 603-620. https:/doi.

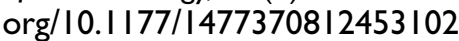

Csabonyi, M., \& Phillips, L. J. (2020). Meaning in life and substance use. Journal of Humanistic Psychology, 60(I), 3-19. https://doi.org/l0. I I77/0022167816687674

Day, A., \& Ward, T. (2010). Offender rehabilitation as a value-laden process. International Journal of Offender. Therapy and Comparative Criminology, 54(3), 289-306. https:/doi. org/I 0.1 I 77/0306624X09338284

De Vries, M., Mann, R. E., Maruna, S., \& Thornton, D. (20/5). An exploration of protective factors supporting desistance from sexual offending. Sex Abuse, 27(I), 16-33. https:/doi. org/I 0.1 I 77// 0790632 |4547582

Doekhie, J., Dirkzwager, A., \& Nieuwbeerta, P. (20I7). Early attempts at desistance from crime: prisoners' prerelease expectations and their postrelease criminal behaviour. Journal of Offender Rehabilitation, 56(7), 473-493. https:// doi.org// 0.1080/10509674.2017.1359223

Emmelkamp, P. M. G., \& Vedel, E. (2006). Evidencebased Treatment for Alcohol and Drug Abuse. Routledge.

Eryilmaz, A. (2018). Comparison of offender and non-offender young men to setting goals for life and attributing meaning to life. Journal of Religion and Health, 57, I350-1362. https://doi. org/10.1007/s 10943-017-0478-x

Frankl, V. E. (2000). El hombre doliente. Herder.

Frankl, V. E. (2003). Ante el vacío existencial. Herder.

Frankl, V. E. (2004). El hombre en busca de sentido. Herder.

Frankl, V. E. (20I8). Logoterapia y análisis existencial. Herder.

Gadd, D., \& Farrall, S. (2004). Criminal careers, desistance and subjectivity: interpreting men's narratives of change. Theoretical Criminology, 8(2), I23-I56. https://doi.org//0. | | 77/| 36248060404224|
George, L., \& Park, C. (2016). Meaning in life as comprehension, purpose, and mattering: toward integration and new research questions. Review of General Psychology, 20(3), 205-220. https://doi.org// 0.1037/gpr0000077

George, L., \& Park, C. (2017). The multidimensional existential meaning scale: a tripartite approach to measuring meaning in life. The Journal of Positive Psychology, I2(6), 613-627. https://doi. org/l0.1080/17439760.2016.1209546

Giordano, P. C., Schroeder, R. D., \& Cernkovich, S. A. (2007). Emotions and crime over the life course: a neo-meadian perspective on criminal continuity and change. American Journal of Sociology, I I 2(6), I603-I66I.

Giordano, P. G., Cernkovich, S. A., \& Rudolph, J. L. (2002). Gender, crime, and desistance: toward a theory of cognitive transformation. American Journal of Sociology, 107(4), 990 1064.

Gottfredson, M. R., \& Hirschi, T. (1990). A General Theory of Crime. Stanford University Press.

Herzog, B. (2016). Entender crimen y justicia: métodos y técnicas de investigación social cualitativa en criminología. Tirant Lo Blanch.

Hirschi, T., \& Gottfredson, M. R. (1983). Age and the explanation of crime. American Journal of Sociology, 89, 552-584.

Howerton, A., Burnett, R., Byng, R., \& Campbell, J. (2009). The consolations of going back to prison: what 'revolving door' prisoners think of their prospects. Journal of Offender Rehabilitation, 48, 439-46I. https://doi. org/l0.1080/105096709029797/0

Kazemian, L., \& Maruna, S. (2009). Desistance from crime. En M. D. Krohn, A. Lizotte \& P. G. Hall (eds.), Handbook on Crime and Deviance (PP. 277-295). Springer.

King, S. (20I 3). Early desistance narratives: a qualitative analysis of probationers' transitions towards desistance. Punishment \& Society, I5(2), |47-165. https://doi.org/10.1 177/ |4624745 | 3477790

Laub, J., \& Sampson, R. (2003). Shared Beginnings, Divergent Lives: Delinquent Boys to Age 70. Harvard University Press.

LeBel, T. P., Burnett, R., Maruna, S., \& Bushway, S. (2008). The 'chicken and egg' of subjective and social factors in desistance from crime. European Journal of Criminology, 5(2), I 3 | - 159. https://doi.org/I0.1 I77//477370807087640

Liem, M., \& Richardson, N. J. (20I4). The role of transformation narratives in desistance among released lifers. Criminal Justice and Behavior, 4I(6), 692-7I2. https://doi.org/l0. I I 77/00938548|35।5445 
Martens, J. A. (2017). Desistimiento criminal en Paraguay. Análisis de los condicionamientos estructurales en el surgimiento de relatos de cesación delictiva. Revista de Estudios Paraguayos, 35(I), 88-122.

Martín, A. M., Padrón, F., \& Redondo, S. (2019). Early narratives of desistance from crime in different prison regimes. The European Journal of Psychology Applied to Legal Context, I I (2), 7I-79. https://doi.org/10.5093/ejpalc2019a2

Martínez, E. (2009). El diálogo socrático en la terapia centrada en el sentido. Colectivo Aquí y Ahora.

Martínez, E., \& Flórez, I. A. (20I5). Meaning-centered psychotherapy: a Socratic clinical practice. Journal of Contemporary Psychotherapy, 45, 37-48. https://doi.org//0.1007/s 108790|4-928I-0

Maruna, S. (200I). Making Good:How Ex-Convicts Reform and Rebuild their Lives. American Psychological Association.

Maruna, S. (2004). Desistance from crime and explanatory style: a new direction in the psychology of reform. Journal of Contemporary Criminal Justice, 20(2), I84-200. https://doi. org/I0.I I 77// 043986204263778

Maruna, S., Wilson, L., \& Kurran, K. (2006). Why God is often found behind bars: prison conversions and the crisis of self-narrative. Research in Human Development, 3(2-3), I6I-184. https:// doi.org// 0.1080/I5427609.2006.9683367

McAdams, D. P. (2008). The Life Story InterviewII. The Foley Center for the Study of Lives, Northwestern University. https://cpb-us-el. wpmucdn.com/sites.northwestern.edu/ dist/4/390 I/files/2020/I I/The-Life-StoryInterview-II-2007.pdf

McAdams, D. P. (20/8). Narrative identity: what is it? What does it do? How do you measure it? Imagination, Cognition and Personality: Consciousness in Theory, Research, and Clinical Practice, 37(3), 359-372. https://doi. org//0.I I77/02762366/8756704

McAdams, D. P., \& McLean, K. C. (20I3). Narrative identity. Current Directions in Psychological Science, 22(3), 233-238. https://doi.org/l0. I I77/096372 I4I3475622

McNeill, F. (2006). A desistance paradigm for offender management. Criminology \& Criminal Justice, 6(I), 39-62. https://doi.org/ 10. I I 77// 748895806060666

McNeill, F., Farrall, S., Lightowler, C., \& Maruna, S. (20I2). How and Why People Stop Offending: Discovering Desistance. Institute for Research and Innovation in Social Services. https:// eprints.gla.ac.uk/79860/ I/79860.pdf
Moffitt, T. (1993). Adolescence-limited and lifecourse persistent antisocial behavior: a developmental taxonomy. Psychological Review, 100(4), 674-70I.

Paternoster, R., Bachman, R., Bushway, S., Kerrison, E., \& O'Connell, D. (20I5). Human agency and explanations of criminal desistance: arguments for a rational choice theory. Journal of Developmental and Life-Course Criminology, I(3), 209-235. https://doi.org/I0.I007/s40865 $-0 \mid 5-0013-2$

Paternoster, R., \& Bushway, S. (2009). Desistance and the feared self: toward an identity theory of desistance. Journal of Criminal Law and Criminology, 99, I I03-I I 56.

Piquero, A. R., Hawkins, J. D., Kazemian, L., Petechuk, D., \& Redondo, S. (20|3). Serie especial: la transición desde la delincuencia juvenil a la delincuencia adulta II. Revista Española de Investigación Criminológica, I I, I-40.

Popp-Baier, U. (2013). Narrative psychology. EncyclopediaofSciences and Religions, I 388- I 394. https://doi.org// 0.1007/978-1-4020-8265 -8 - 780

Presser, L. (2016). Criminology and the narrative turn. Crime Media Culture, I2(2), I37-I5I. https://doi.org/10.1 I77/1741659015626203

Presser, L., \& Sandberg, S. (20I5). Narrative Criminology. Understanding Stories of Crime. New York University Press.

Presser, L., \& Sandberg, S. (2019). Narrative criminology as critical criminology. Critical Criminology, 27, |3|-|43. https://doi.org//0. 1007/s 106 I 2-019-09437-9

Redondo, S. (2017). Evaluación y tratamiento de delincuentes jóvenes y adultos. Pirámide.

Redondo, S., \& Garrido, V. (20/3). Principios de criminología ( $4^{\mathrm{a}}$ ed.). Tirant Lo Blanch.

Redondo, S., Martínez-Catena, A., \& Andrés-Pueyo, A. (20I2). Intervenciones con delincuentes juveniles en el marco de la justicia: investigación y aplicaciones. Revista de Psicología y Educación, I I (2), I43-169.

Reker, G. T. (2000). Theoretical perspective, dimensions, and measurement of existential meaning. En G. T. Reker \& K. Chamberlain (eds.), Exploring Existential Meaning: Optimizing Human Development across the Life Span (pp. 39-55). Sage Publications.

Rocque, M. (2017). Desistance From Crime: New Advances in Theory and Research. Palgrave Macmillan.

Ronel, N., \& Elisha, E. (20I I). A different perspective: introducing positive criminology. International Journal of Offender Therapy and Comparative Criminology, 55(2), 305-325. https://doi. org//0.1 I 77/0306624X09357772 
Sampson, R. J., \& Laub, J. H. (2005). A life-course view of the development of crime. The Annals of the American Academy of Political and Social Science, 602(I), I2-45.

Sampson, R., \& Laub, L. (1993). Crime in the Making: Pathways and Turning Points Through Life. Harvard University Press.

Sandberg, S., \& Ugelvik, T. (2016). The past, present, and future of narrative criminology: a review and an invitation. Crime Media Culture, 12(2), 129-136. https://doi.org/I0. II77/I74I6590I6663558

Souza, K. A., Lösel, F., Markson, L., \& Lanskey, C. (20/3). Pre-release expectations and postrelease experiences of prisoners and their (ex-) partners. Legal and Criminological Psychology, 20(2), 306-323. https://doi.org/ I0. I I I I/lcrp. 12033

Stone, R. (20/6). Desistance and identity repair: redemption narratives as resistance to stigma. The British Journal of Criminology, 56(5), 956-975. https://doi.org//0.1093/bjc/azv08।

Sweeten, G., \& Khade, N. (2018). Equifinality and desistance: which pathways to desistance are the most traveled in young adulthood? Journal of Developmental and Life-Course Criminology, 4, 369-394. https://doi.org//0.1007/s40865$018-0092-y$
Thornberry, T. P., Giordano, P. C., Uggen, C., Matsuda, M., Masten, A. S., Bulten, E., Donker, A., Petechuk, D., \& Redondo, S. (20I3). Serie especial: la transición desde la delincuencia juvenil a la delincuencia adulta III. Revista Española de Investigación Criminológica, I I, I -49.

Ward, T. (2017). Prediction and agency: the role of protective factors in correctional rehabilitation and desistance. Aggression and Violent Behavior, 32, 19-28. https://doi. org/l0.1016/j.avb.2016.11.012

Ward, T., \& Gannon, T. A. (2006). Rehabilitation, etiology, and self-regulation: the comprehensive good lives model of treatment for sexual offenders. Aggression and Violent Behavior, II, 77-94. https://doi.org/I0.1016/j. avb.2005.06.00I

Ward, T., \& Maruna, S. (2007). Rehabilitation: Beyond the Risk Paradigm. Routledge.

Ward, T., Yates, P. M., \& Willis, G. M. (20/2). The good lives model and the risk need responsivity model: a critical response to Andrews, Bonta, and Wormith (2011). Criminal Justice and Behavior, 39(1), 94-II0. https://doi.org/ | 0.I I77/00938548 I I 426085

Weaver, B. (2019). Understanding desistance: a critical review of theories of desistance. Psychology, Crime \& Law, 25, 64I-658. https:// doi.org//0.1080/10683/6X.2018.1560444 